\title{
ALAIN TOURAINE E 0 BRASIL: ATORES SOCIAIS E DEPENDÊNCIA EM DIÁLOGOS DOS ANOS 1970'1
}

Flávio da Silva Mendes

é doutor em Sociologia pela Universidade Estadual de Campinas (Unicamp) e atualmente conclui o pós-doutorado pelo departamento da área na mesma universidade. Campinas, SP, Brasil. E-mail: <flavi085@gmail.com>

Orcid: 0000-0001-6884-2333

http://dx.doi.org/10.1590/0102-097129/106

Desde seus primeiros contatos com a América Latina, na década de 1950, Alain Touraine percebeu que uma sociologia dedicada a essa região não poderia replicar todas as teorias e conceitos clássicos da disciplina. Imersos em processos tardios de industrialização, países como Chile, Brasil e Argentina, com os quais ele teve maior contato, não espelhavam a estrutura social da França ou da Inglaterra do século XIX, período no qual essas nações se modernizaram ou, em outros termos, viram se afirmar no interior de suas fronteiras o modo de produção capitalista. Nas sociedades periféricas, a dependência econômica externa contribuiria para a reprodução de uma realidade complexa, que combina traços autoritários e oligárquicos - herdados do período colonial - com pressões para a consolidação de uma ordem social democrática e burguesa. Um projeto conduzido por Estados que se esforçam para conciliar interesses opostos defendidos por classes sociais frágeis: de um lado os operários, que transitaram de forma rápida e

1 Este texto apresenta resultados parciais de uma pesquisa financiada pela Fundação de Amparo à Pesquisa do Estado de São Paulo (Fapesp). 
desorganizada do meio rural para o urbano-industrial e, de outro, uma burguesia que tenta impor sua dominação interna sobre trabalhadores e a velha oligarquia, enquanto sofre a pressão da dependência externa. Desvendar a conduta desses atores era o que mais interessava a Touraine, afinal ele definia a ação e os conflitos sociais como principais objetos da sociologia: apenas a partir desses temas seria possível compreender o movimento que permite às sociedades produzirem a si mesmas e se transformarem.

Essa postura o aproximou de outros intelectuais latino-americanos que também pensavam os desafios da modernização periférica. Neste artigo, analiso sob quais condições essa aproximação se transformou em diálogo, sobretudo a partir da passagem do sociólogo francês pela Universidade de São Paulo no início dos anos 1960, e como esse intercâmbio se reproduziu nos anos seguintes. Parte deste texto será dedicada à exposição e discussão do conteúdo de dez teses sobre o Brasil orientadas por Touraine na França durante a década de 1970. Através de seus objetos e hipóteses, essas pesquisas revelam boa parte dos termos em que se deu o intercâmbio entre a perspectiva tourainiana e a sociologia brasileira, num período no qual esta se esforçava para compreender as causas do fracasso do projeto de modernização concebido no período pré-1964.

\section{Touraine e a sociologia francesa no pós-guerra}

Antes de passar à análise das teses sobre o Brasil orientadas por Touraine, tema central deste artigo, apresento alguns dados sobre a trajetória do sociólogo e a situação da sociologia francesa entre as décadas de 1950 e 1960, período em que ele ingressou no espaço acadêmico. Analisar esse contexto é importante para conhecermos os temas sobre os quais Touraine se interessou e seus principais interlocutores. O próprio sociólogo faz questão de começar muitas de suas exposições, escritas ou orais, com um panorama da vida intelectual europeia a partir do início do século XX no qual 
a noção de crise é central. Para ele, o florescimento de ideias ligado ao otimismo iluminista, que marcou a produção científica nos séculos anteriores - já abalado pelo ciclo revolucionário do XIX -, foi enfim derrubado pelo início da Primeira Guerra Mundial, evento que radicalizou os conflitos em solo europeu. Além das duas grandes guerras, tragédias como o holocausto imprimiram reviravoltas no pensamento social e estimularam reflexões como as produzidas pela sociologia crítica alemã. Mas, para Touraine, esta escola era uma exceção: um olhar mais amplo sobre o velho continente revelava, segundo ele, a "carência de um modelo europeu", sobretudo diante da expansão da sociologia estadunidense.

Nascido em 1925 na região da Normandia, Touraine cresceu em Paris. Filho de um médico, ele atravessou o entreguerras num ambiente que definiu como burguês-aristocrata, decadente, afetado pela ruína de valores que compunham o modo de vida francês ${ }^{2}$. Na escola preparatória, ele teve a sensação de viver num mundo erudito, mas fechado em si, de costas para o que se passava ao seu redor. Alheio, por exemplo, à ocupação nazista de Paris, entre 1940 e 1944. Uma impressão que se repetiu após seu ingresso na École Normale Supérieure, em 1945, para cursar História. Incomodado, ele decidiu se afastar das aulas e foi ao norte da França para trabalhar em minas de carvão, em meio a operários franceses, poloneses e alemães. Neste período, enquanto se interessava por questões relacionadas à consciência e organização dos trabalhadores, ele leu Les problèmes humains du machinisme industriel, livro de Georges Friedmann, com quem entrou em contato em seguida. O sociólogo, pioneiro em pesquisas sobre trabalho, convenceu-o a concluir a licença em História para em seguida ingressar em seu laboratório, vinculado ao Centre National de la Recherche Scientifique (CNRS), em 1950.

\footnotetext{
2 "Era um mundo no qual o dinheiro certamente não faltava, mas onde o exército e a Igreja [le sabre et le goupillon] eram mais importantes ou em todo caso mais respeitados que a conta no banco" (Touraine, 1977, pp. 12).
} 
Enquanto decidia sua área de estudos - a sociologia do trabalho - Touraine também se interessava por questões teóricas e metodológicas. Com o objetivo de se aprofundar nestes temas, viajou aos Estados Unidos em 1952, financiado por uma bolsa da Fundação Rockfeller. Lá, teve contato com o funcionalismo estrutural de Talcott Parsons, que se tornaria o alvo de suas críticas mais duras. Também passou por Columbia, Nova Iorque e Chicago, onde se sentiu mais à vontade em meio à efervescência dos estudos urbanos. A excursão pela América do Norte se justificava pela convicção de que lá a sociologia era mais atenta às questões sociais de seu tempo e, por isso, mais respeitada e consolidada como disciplina do que na França. Impressão compartilhada por Michel Crozier, colega francês que participaria, em 1959, da criação da revista Sociologie du Travail ao lado de Touraine e Jean-Daniel Reynaud. Crozier considerava que havia um vazio na sociologia francesa quando sua geração chegou 100 à academia. Um cenário produzido entre as duas grandes guerras, quando preocupações políticas e filosóficas teriam ofuscado reflexões sociológicas e dificultado a realização de pesquisas empíricas. Aquela era, para ele, uma geração sem "pais", ou seja, sem grandes referências intelectuais, o que permitiria certa ousadia. Por outro lado, a fragilidade do debate teórico era compensada por um empirismo radical: ele e seus colegas "dedicavam-se ao trabalho de campo como se este fosse uma religião" (Crozier, 1996, pp. 10). Uma postura que seria premiada quando a sociologia francesa - sobretudo a vertente dedicada a temas ligados ao trabalho - passou a ser valorizada e estimulada, inclusive pelo Estado francês. ${ }^{3}$ Ela passou a atrair muitos estudantes

\footnotetext{
${ }^{3}$ Em 1951, a criação do Institut des Sciences Sociales du Travail, a partir da iniciativa do Ministério do Trabalho em parceria com a Universidade de Paris, favoreceu o avanço dos estudos nesta subárea. Os financiamentos provinham do Estado francês com o apoio dos Estados Unidos, através do Plano Marshall. Essa história é detalhada por Lucie Tanguy (2008).
} 
recém-formados, como os que se integravam ao grupo de pesquisas liderado por Touraine, Crozier e Reynaud. ${ }^{4}$

Porém, o reconhecimento não impediu que esses pesquisadores refletissem sobre suas referências teóricas e os objetos de suas análises. A partir do final dos anos 1950 eles se distanciaram do marxismo, que servia de base de inspiração filosófica para o grupo, ainda que de forma não dogmática. Eles também passaram a notar, nos resultados de suas pesquisas de campo, alguns elementos contraditórios que pareciam negar a hipótese da centralidade do trabalho que orientara a primeira agenda de investigações. A partir dessas constatações, decidiram abandonar a revista Sociologie du Travail em 1967, cerca de um ano antes da agitação estudantil que impactaria de forma definitiva as reflexões de Touraine.

É possível destacar três diferentes fases no pensamento de Alain Touraine, reconhecidas pelo próprio autor, por alguns de seus colegas e por muitos críticos de seus textos: 1) a sociologia das sociedades ditas industriais, com foco no trabalho, que durou até 1967; 2) a sociologia das sociedades que chamou de pós-industriais, nas quais se sobressaem os novos movimentos sociais, na qual se engajou entre $1967 \mathrm{e}$ 1992; e, por fim, 3) a sociologia do sujeito, à qual tem se dedicado desde o lançamento de Critique de la modernité, em 1992. Apesar das muitas mudanças, há também elementos fundamentais comuns que atravessam todas as fases, o que justifica esta breve introdução ao seu pensamento. Touraine sempre sublinhou a importância do trabalho de campo, pelo qual se interessou desde sua experiência entre operários de minas de carvão no norte da França. Além da base empírica, sua sociologia foi concebida como intimamente colada à reflexão histórica, considerada fundamental para escapar de

\footnotetext{
${ }^{4}$ As impressões de Touraine e Crozier sobre a sociologia francesa devem ser compreendidas como discursos engajados num conflito em torno da refundação da disciplina. Para uma análise detalhada deste momento, ver Chapoulie (1991).
} 
explicações rígidas e deterministas. Por fim, o objetivo principal dessa disciplina, para ele, seria sempre a compreensão dos atores e dos conflitos sociais. Esses pressupostos acompanharam o sociólogo mesmo quando voltou sua atenção para as "sociedades dependentes", como mostrarei a seguir.

\section{América Latina e Brasil: primeiros contatos e a construção de um modelo}

Em 1956, a partir de uma demanda da Universidade do Chile, Friedmann enviou Touraine a Santiago para que ele apoiasse a criação de um centro de estudos dedicado à sociologia do trabalho. Durante seu breve período no país, ele realizou algumas pesquisas, sobretudo sobre operários mineiros, e conheceu sua futura esposa, chilena. Em 1960, ele chegaria à Universidade de São Paulo graças a um convite semelhante, dessa vez feito pelo sociólogo Fernando de Azevedo, que buscava auxílio para a formulação de uma 102 agenda de pesquisas sobre a sociedade industrial.

Quando chegou a São Paulo, em 1959-60, Touraine se impressionou com o ambiente intelectual e com a qualidade dos jovens pesquisadores da Faculdade de Filosofia da USP. Outro fato que chamou sua atenção foi a divisão da área de sociologia: "na USP nessa época havia duas cadeiras, que nós chamávamos constantemente a cadeira americana e a cadeira francesa. A cadeira americana era dirigida por Florestan Fernandes. A outra cadeira, de [Fernando de] Azevedo, nós chamávamos de cadeira francesa" (informação verbal). ${ }^{5}$

A definição de Touraine - apoiada numa oposição entre Estados Unidos e França que correspondia aos conflitos do meio acadêmico de seu país - é imprecisa para caracterizar as duas cadeiras da USP. Porém, a partir de um ponto de vista original, ela põe em relevo divergências que existiam

\footnotetext{
${ }^{5}$ Entrevista cedida em fevereiro de 2018.
} 
na sociologia brasileira e na Escola Paulista, em particular, agitada por intensos debates sobre a institucionalização da disciplina e o papel do sociólogo. Na Faculdade de Filosofia da USP, que iniciou suas atividades em 1934 sob a influência de uma missão francesa de professores, a década de 1950 foi de afirmação de um quadro docente já composto majoritariamente por brasileiros, muitos dos quais pretendiam renovar as práticas de ensino e pesquisa. Em 1954, quando Florestan Fernandes assumiu a cadeira I, até então dirigida por Roger Bastide, ele passou a liderar esse esforço.

A partir desse momento, alguns daqueles que até então se autodenominavam sociólogos deslocaram-se para outras áreas de conhecimento (como a estética e a literatura), outros permaneceram na sociologia, mas transferiram-se para a cátedra contraposta à de Florestan Fernandes, a Cadeira de Sociologia II. (Pulici, 2007, pp. 99-100)

Os textos-manifestos publicados por Florestan e alguns de seus auxiliares ${ }^{6}$ enfatizavam a necessidade de a sociologia se diferenciar de outras disciplinas para se afirmar como ciência. Também era fundamental romper com a tradição ensaística, valorizar a pesquisa empírica e se dedicar a discussões teóricas e metodológicas. Não surpreende, portanto, que Touraine - que defendia princípios semelhantes para a sociologia de seu país - se sentisse mais à vontade no diálogo com auxiliares de Florestan. Simpático pelo debate que se produzia na cadeira I, ele sugeriu que seus membros assumissem a liderança do novo centro de pesquisas sobre trabalho e sociedade industrial que seria criado:

\footnotetext{
${ }^{6}$ Na cadeira I destacavam-se nomes como Fernando Henrique Cardoso, Octavio Inanni, Marialice Foracchi e Maria Sylvia de Carvalho Franco. Na cadeira II, os mais conhecidos eram Antonio Candido, Ruy Galvão de Andrada Coelho e Maria Isaura Pereira de Queiroz. Uma lista completa dos integrantes das duas cátedras entre 1954 e 1969 foi elaborada por Pulici (2007, pp. 119-120).
} 
Eu fiz meu relatório diante das duas [cadeiras] e me perguntaram se havia alguma recomendação do que fazer, de quem deveria se ocupar desse novo centro de pesquisas. Eu disse: "olha, vocês é que devem decidir, mas eu estou muito impressionado por um assistente da outra cadeira, da cadeira de Florestan, que se chama Fernando Henrique Cardoso". (informação verbal) ${ }^{7}$

Pouco depois, o Centro de Sociologia Industrial e do Trabalho (Cesit) foi criado junto à cadeira I. A passagem de Touraine pela USP produziu alguns vínculos duradouros: Fernando Henrique Cardoso, Azis Simão ${ }^{8}$ e Juarez Brandão Lopes ${ }^{9}$ publicaram artigos no número especial "Ouvriers et syndicats d'Amérique Latine” de Sociologie du Travail, lançado em 1961. Cardoso ainda publicou outros dois artigos na revista, em 1963 e 1967, mesmo ano em que Touraine voltou ao Brasil como professor visitante. Cardoso foi, em 104 seguida, lecionar por um semestre em Nanterre (Romão, 2006). Nos anos 1970, os laços de Touraine com o Brasil seriam renovados: durante aquela década ele orientou nove teses de doutorado dedicadas ao país. A primeira foi defendida em 1973 e a última em 1980. As pesquisas mais antigas tiveram início ainda no final dos anos 1960 e sofreram com os efeitos negativos da ditadura brasileira sobre a possibilidade de realização de trabalhos de campo. Também trazem reflexões políticas coladas ao esforço de interpretação da conjuntura nacional. Entre os pesquisadores, eram sete brasileiros, uma belga (Ghislaine Duque) e uma francesa (Christine Apesteguy). Cinco eram vinculados à Universidade de Nanterre e quatro à École de Hautes

\footnotetext{
7 Entrevista cedida em fevereiro de 2018.

8 Apesar de vinculado à cadeira II, Simão foi um dos pioneiros em pesquisas sobre operários industriais (Lopes, Peçanha e Ramalho, 2012).

9 Interessado pela consciência operária - tema favorito de Touraine -, Lopes também tinha em seu currículo uma passagem pela Universidade de Chicago, nos anos 1950.
} 


\section{Études en Sciences Sociales (Tabela 1). A maioria seguiu carreira acadêmica no Brasil. ${ }^{10}$}

Tabela 1

Teses sobre o Brasil orientadas por Alain Touraine nos anos 1970

\begin{tabular}{|l|l|c|c|}
\hline \multicolumn{1}{|c|}{ Autor } & \multicolumn{1}{|c|}{ Título } & Instituição & Ano \\
\hline Andrea Loyola & Les ouvriers et le populisme & Nanterre & 1973 \\
\hline Aspásia Camargo & $\begin{array}{l}\text { Brésil, Nord-Est: mouvements paysans et crise } \\
\text { populiste }\end{array}$ & EHESS & 1973 \\
\hline $\begin{array}{l}\text { Ilse Scherer- } \\
\text {-Warren }\end{array}$ & $\begin{array}{l}\text { Le syndicat et le changement de la société } \\
\text { agraire dans le Rio Grande do Sul }\end{array}$ & Nanterre & 1973 \\
\hline Décio Saes & Classe moyenne et système politique au Brésil & EHESS & 1974 \\
\hline $\begin{array}{l}\text { Christine } \\
\text { Apesteguy }\end{array}$ & $\begin{array}{l}\text { L'intervention fédérale en Amazonie : éléments } \\
\text { pour une définition de l'État militaire au Brésil }\end{array}$ & Nanterre & 1976 \\
\hline Ligia Maria Pereira & $\begin{array}{l}\text { Bourgeoisie industrielle et capital étranger au } \\
\text { Brésil (1956-1977) }\end{array}$ & Nanterre & 1978 \\
\hline Julio Cesar Grieco & $\begin{array}{l}\text { L'union fait la faiblesse : le commandement } \\
\text { général des travailleurs et la politique brésilienne } \\
\text { (1962- 1964) }\end{array}$ & EHESS & 1979 \\
\hline $\begin{array}{l}\text { Maria das Graças } \\
\text { Grossi }\end{array}$ & $\begin{array}{l}\text { Système politique et développement } \\
\text { économique: le cas du Minas Gerais }\end{array}$ & Nanterre & 1979 \\
\hline Ghislaine Duque & $\begin{array}{l}\text { Casa Nova : interventions du pouvoir et stratégies } \\
\text { paysannes. Un « municipe » du « sertão bahiano » } \\
\text { à I' heure de la modernisation }\end{array}$ & EHESS & 1980 \\
\hline
\end{tabular}

Fonte: Pires-Sabóia (2000).

Seria natural pressupor que eles compartilhavam as preocupações que Touraine expressava em sua nova fase de trabalho, inaugurada no final da década anterior; mas a equação não é tão simples. Enquanto o sociólogo francês voltava sua atenção ao estudo do que passou a chamar de "sociedades pós-industriais" e à conduta dos atores que lhe seriam típicos - os

\footnotetext{
10 Segue uma lista com a principal vinculação institucional dos que ingressaram como pesquisadores e docentes em universidades brasileiras: Andrea Loyola passou à área de estudos sobre medicina social e ingressou na Universidade Estadual do Rio de Janeiro, mesma instituição à qual se vinculou Aspásia Camargo. Décio Saes lecionou na Universidade Estadual de Campinas. Lígia Maria Pereira trabalhou junto à Universidade Federal de Minas Gerais. Ghislaine Duque foi professora da Universidade Federal de Campina Grande.
} 
novos movimentos sociais -, seus orientandos dedicados a pesquisas sobre o Brasil eram estimulados por outras questões. Preocupados em compreender a crise do populismo, do nacional-desenvolvimentismo e as raízes do regime autoritário, eles pensavam numa chave de análise mais classista, atentos à organização de camponeses, trabalhadores, classes médias e burguesia. De sindicatos, partidos e do Estado, tudo num contexto - que todos fizeram questão de sublinhar marcado pela industrialização tardia. Um "modelo de desenvolvimento dependente", também imaginado por Touraine, era a chave para pensar o Brasil e a América Latina.

O sociólogo francês construiu esse modelo a partir do diálogo com autores latino-americanos, com os quais compartilhava a certeza de que os obstáculos à modernização dos países da região não eram idênticos aos enfrentados pelos países centrais, pioneiros da expansão capitalista. Nestes, a consolidação da nova ordem social e do novo modo de produção ocorreu 106 sob controle estrito da burguesia, que se impunha frente às forças sociais do antigo regime. O surgimento de um discurso contestatório só se deu mais tarde, em meio à lenta integração dos setores dominados à política. Em paralelo, ainda de acordo com Touraine, surgia um pensamento social capaz de olhar para o sistema em sua totalidade e, através de sua crítica, contestar sua suposta naturalidade. Em resumo: ao final do processo, economia, política e ideologia estavam articuladas e davam sentido à experiência moderna. ${ }^{11}$

Para Touraine, este caminho em sociedades dependentes é diverso e incompleto. Em primeiro lugar, porque a expansão capitalista e a consolidação de uma ordem burguesa ocorrem tardiamente, num momento em que os setores dominados já são capazes de exercer maior pressão política. A luta pela integração das massas pressiona o sistema político

\footnotetext{
11 Esta sequência aparece descrita com mais detalhes em Production de la société e Un désir d'histoire, além de outros trabalhos em que ele se dedicou à elaboração de uma teoria social da modernidade ou da modernização.
} 
e prejudica a formação de uma hegemonia burguesa, o que ajuda a explicar a força do Estado populista e sua estratégia de conciliação de interesses antagônicos. Neste cenário, a análise das relações sociais não pode seguir uma abordagem tradicional, baseada em classes, pois estas não aparecem tão bem estruturadas quanto nas sociedades industriais típicas. ${ }^{12}$ Outra diferença: as relações entre o político, o social e o econômico aparecem de forma desarticulada, sobretudo quando tomamos como parâmetro a história da expansão capitalista na Europa. Isso ocorre graças à existência de um fator heterônomo, a dominação econômica externa:

No mundo latino-americano, as formas da mudança histórica - ou seja, a dependência em relação ao estrangeiro - comandam a vida social mais diretamente do que as leis internas do sistema capitalista. É um erro querer analisar essas sociedades como analisamos as nossas. Não que elas careçam de realidade própria ou que sejam inteiramente redutíveis a uma lógica de lucro que se elabora num lugar distante, mas porque a dependência cria sociedades de um tipo particular. Infelizmente as sociedades dependentes são ainda pouco estudadas: é por isso que eu lhes dediquei um livro em 1976. Elas não são colônias, elas têm uma ampla autonomia. Mas a dependência lhes vira do avesso: nelas a ideologia domina a política que domina a economia no nível nacional, enquanto ao mesmo tempo um poder econômico dirige do exterior seu funcionamento. (1977, pp. 162, tradução nossa $)^{13}$

\footnotetext{
12 Vale ressaltar que, para Touraine, as classes sociais também perdem importância nos países centrais a partir da transição à sociedade pós-industrial e da emergência dos novos movimentos sociais.

13 A derrota da Unidade Popular no Chile influenciou a visão pessimista de Touraine sobre a América Latina. O sociólogo estava no país quando ocorreu o golpe militar contra Salvador Allende, em 1973. Em sua análise do período de conflitos que marcou o mandato do presidente socialista, ele enfatiza a disparidade entre a força de "ações de tipo político-ideológicas" e a "fraca capacidade de desenvolver uma política econômica” (1977, pp. 162).
} 
Não por acaso, a sociologia do desenvolvimento ocupa boa parte do pensamento social desses países: ela é, segundo Touraine, antiestruturalista, mais atenta ao movimento e à transformação do que as formas consolidadas. Por isso a noção de modo de produção - sincrônica, mais adequada à sociologia das sociedades industriais - lhe é menos cara do que a de modo de desenvolvimento, diacrônica, capaz de revelar os conflitos que envolvem o processo de modernização inacabado. Outra afirmação importante: Touraine sugere que essa sociologia do desenvolvimento deve valorizar as dinâmicas internas e os conflitos entre os atores sociais, pois estes conservariam uma autonomia relativa em relação à dominação externa, à dependência. Este argumento seria um dos mais fortes e originais presente no livro Dependência e desenvolvimento na América Latina, de Fernando Henrique Cardoso e Enzo Faletto. Publicado em 1967, ele é considerado por Touraine a 108 maior contribuição da sociologia latino-americana ao debate sociológico do século XX em geral:

foi o grupo de Cardoso que teve um raciocínio que eu acho muito simples e muito claro. Não são detalhes. São coisas enormes, mas simples. Quando Cardoso diz: "vocês falam de dependência, é claro que há dependência. A questão não é essa. A questão é: não há nada além da dependência?”. Ora, a gente não pode dizer isso. [...] Era um tanto genial de sua parte, não esquecer a herança marxista: a luta de classes existe. [...] Ele fez um raciocínio de uma simplicidade formidável, este pequeno livro é uma maravilha. Escrito com ar claro, simplicidade, nenhum jargão, nenhum debate pessoal. Direto ao ponto. Os atores políticos têm uma liberdade, eles não são determinados. Veja só! Na escala da sociologia do século XX, que nasceu no final do XIX, este é um dos debates maiores. Um dos debates mais importantes do século XX, ao lado da 
questão sobre totalitarismo, que dominou a Europa. (informação verbal) ${ }^{14}$

Neste aspecto, a proposta da teoria da dependência ia ao encontro das reflexões teóricas de Touraine. Do seu ponto de vista, definido como "acionalista", a compreensão de uma sociedade deve sempre partir de sua dinâmica interna, da forma como os atores em conflito produzem sua história. Ela "não deve nunca aparecer como uma situação, como uma organização social, mas como uma ação" (1973, pp. 173, tradução nossa). Essa proposta foi apresentada em sua tese de doutorado Sociologie de l'action, de 1965, elaborada em oposição direta ao funcionalismo. Enquanto este privilegiava o estudo das condições de reprodução da sociedade, Touraine propunha uma sociologia voltada a decifrar o que torna possível sua produção e conclui que os conflitos entre os atores estão na base de todo processo de transformação. Essa proposta teórica foi ampliada e aprimorada em Production de la Société (1973), na qual são apresentados três níveis de ação social, definida como objeto maior da sociologia. O primeiro, mais elevado, é o da disputa pelo modelo cultural que rege a sociedade, ao qual Touraine se refere com o conceito de historicidade. Logo abaixo, encontraríamos o sistema institucional, onde ocorrem os conflitos em torno das normas internas que regem a sociedade e suas instituições. E há, por fim, o nível do sistema organizacional ou das práticas sociais em sentido amplo, que devem ser compreendidas a partir de sua articulação com as normas e com a forma da dominação social. Essa distinção é fundamental, pois, para Touraine, só podem ser chamados de "movimentos sociais" aqueles atores que são capazes de agir no nível mais elevado. Ou seja: que conseguem questionar a dominação social e impulsionar processos

\footnotetext{
14 Entrevista cedida em fevereiro de 2018.
} 
de transformação social. Uma posição ocupada pelo movimento operário nas sociedades industriais e pelos novos movimentos sociais nas pós-industriais.

Acredito, porém, que há uma contradição ou questões mal resolvidas entre essa teoria, concebida como flexível, e as conclusões que ele deriva da construção do "modelo dependente", bastante rígidas: em muitos textos ele afirma que os atores sociais de países periféricos e dependentes seriam incapazes de se contrapor à dominação externa e, portanto, nunca seriam atores plenos:

A América Latina é um continente de atores sem ação. [...] O que eu chamei de desarticulação da ação coletiva indica que o excesso de autonomia das ideologias e mesmo da ação política em relação à realidade econômica engendra uma mobilização social e política mais fictícia do que real, mais teatral do que eficaz. O que nos leva a uma constatação sem surpresa: a América Latina é apenas parcialmente moderna; ela tem uma capacidade insuficiente de ação técnica, econômica, social e política. (Touraine, 1988, pp. 469)

Alan Scott (1996) notou incoerências semelhantes entre a teoria acionalista e a noção de sociedade pós-industrial, que Touraine passou a adotar a partir da década de 1970. Neste outro tipo de sociedade, os atores também apareceriam enfraquecidos frente a uma estrutura de dominação que lhes escapa. Ou seja: enquanto sua proposta teórica seria antideterminista, a definição de um modelo rígido de sociedade apontaria em direção oposta. Tharailath Oommen (1996) parte de crítica semelhante para contestar a hipótese de que movimentos sociais em sentido pleno - ou seja, capazes de colocar em questão uma ordem social - não podem aparecer em sociedades totalitárias ou colonizadas. Destaco esses pontos porque eles são centrais para compreender o "modelo de desenvolvimento dependente", que 
serviu de base não apenas para os trabalhos de Touraine sobre a América Latina, mas também para as pesquisas que seus orientandos realizaram sobre o Brasil durante os anos 1970: atores sociais fracos, dependência e desarticulação estão entre as ideias-chave de muitos desses trabalhos.

\section{As pesquisas sobre o Brasil: temas, hipóteses e referências}

Andrea Loyola defendeu sua tese - Les ouvriers et le populisme. Les attitudes ouvrières à Juiz de Fora - em 1973. A pesquisa parte de uma questão cara à sociologia do desenvolvimento: como explicar as formas de ação e de consciência de trabalhadores recém-chegados ao espaço urbano? Este tema aparecia tanto em estudos de Touraine na França e no Chile quanto em textos de Juarez Brandão Lopes, como o livro Sociedade industrial no Brasil. Nesta obra, a hipótese central é de que a persistência de valores tradicionais nas atitudes operárias decorre de sua origem rural, o que explica tanto a dificuldade de adaptação ao meio urbano quanto os obstáculos à ação coletiva. Uma pesquisa de campo realizada por Loyola junto a operários de Juiz de Fora teria mostrado que as origens sociais não bastam para esclarecer a conduta dos trabalhadores. Esta seria multidimensional: resultado do cruzamento de influências do meio em que vivem - a fábrica, a cidade - e do contexto nacional (populismo, dependência, autoritarismo etc.). Nesta forma de abordagem, o Estado ganha destaque, pois ele é o responsável por definir "as regras do jogo" no qual os atores estão inseridos. Neste sentido, ela sustenta que seria impossível compreender as atitudes e expectativas da nascente classe trabalhadora brasileira sem considerar o peso da ideologia nacional-desenvolvimentista.

Outro trabalho que toma como referência os debates sobre desenvolvimento é Le syndicat et le changement de la société agraire du Rio Grande do Sul, tese defendida por Ilse SchererWarren em 1973. Nela, a categoria de "economia nacional 
dependente" aparece logo no início da introdução. Essa é definida, sobretudo, a partir da coexistência de estruturas modernas e arcaicas, como as que ela encontrou no movimento camponês do Rio Grande do Sul, "setor subordinado" que é objeto da pesquisa. A "situação de dependência” é o ponto de partida para a definição do método de análise, que deve contemplar duas visões complementares. A primeira é histórico-estrutural, concentrada sobre aspectos econômicos, políticos e culturais no interior da dinâmica de mudança da "sociedade global". A segunda deve dar conta da situação de dependência em si, ou seja, da relação que a sociedade periférica estabelece com o centro e como essa influencia suas características internas: seu sistema econômico (relações de produção, de propriedade etc.), político (Estado, partidos e ideologia) e social (estrutura de classes e ideológica).

Aspásia Camargo também realizou sua pesquisa sobre o movimento camponês; porém, em Brésil Nord-Est: mouvements 112 paysans et crise populiste, tese defendida em 1973, sua atenção está voltada para o Nordeste, mais precisamente sobre o peso que as lutas de trabalhadores rurais da região exerceram sobre o contexto de crise política nacional do início dos anos 1960. Camargo anuncia na introdução à tese que não pretende se dedicar a aspectos “comunitários”, considerados típicos de movimentos camponeses, mas à sua ação política. Para ela, a mobilização de trabalhadores rurais no pré-1964 tinha a capacidade de denunciar o caráter limitado do desenvolvimento e as relações entre oligarquia latifundiária e Estado. Atraía, portanto, a atenção de intelectuais, de partidos políticos de esquerda e do presidente João Goulart, que pretendia encontrar neste setor social a base de sustentação política necessária para contornar a crise inaugurada pela renúncia de seu antecessor, Jânio Quadros. Os camponeses seriam naquele contexto um ator tão importante quanto foram os trabalhadores urbanos na Era Vargas. Camargo tenta decifrar a natureza contraditória 
de um Estado populista que é, ao mesmo tempo, um agente de enquadramento de forças políticas heterogêneas e um fator de impulsão à mobilização popular. Um Estado ator que se afasta, portanto, de definições clássicas, que lhe atribuem o papel de árbitro dos conflitos sociais ou de defensor exclusivo dos interesses das classes dominantes. Ambas seriam inadequadas para explicar seu lugar em sociedades dependentes, compostas por atores sociais fracos. No final da tese, há uma reflexão muito próxima às preocupações de Touraine sobre a viabilidade de movimentos sociais fortes, capazes de questionar uma forma de dominação social, no interior de nações dependentes, desarticuladas, submetidas a interesses externos:

Contudo nós tendemos a acreditar que movimentos autônomos não terão lugar numa sociedade enquanto ela continue tributária de um sistema internacional que define os parâmetros de sua vida econômica, perturbam a composição de sua classe dominante, introduz tecnologias que desequilibram o mercado de trabalho, acentuam a distância entre operários qualificados e a massa de trabalhadores, entre a cidade e o campo, entre as regiões, provocam o aumento imensurável do desemprego, dos sub-proletários, dos marginais, em suma - desarticulam as relações sociais. (Camargo, 1973, pp. 392)

Décio Saes também dedicou sua pesquisa a um ator social e seu lugar na política brasileira. Em Classe moyenne et système politique au Brésil, tese defendida em 1974, a protagonista é a classe média, objeto recorrente de reflexões na América Latina graças à sua importância nos processos de modernização - em que se destacara na crítica ao sistema oligárquico - e, mais tarde, na crise do populismo, quando assumiria um caráter mais conservador, como aliada das classes dominantes. Essas seriam as duas visões hegemônicas entre 
intelectuais da região, que passaram da exaltação às classes médias - por exemplo o caso do tenentismo no Brasil - ao desprezo ou desconfiança diante de sua nova feição, retrógrada e tecnocrata. Saes toma distância dessas leituras e pretende relativizar o diagnóstico de "degradação" dos setores médios. Para tanto, analisa sua postura ao longo do processo de industrialização no Brasil, sobretudo durante o período conhecido como de "substituição de importações", em que estes se expandiram junto com o crescimento do setor de serviços e conquistaram maior força política.

Saes também parte de uma análise histórico-estrutural que toma as relações entre os atores sociais e o sistema econômico e político brasileiros ao longo do tempo a partir de mudanças importantes da sociedade durante a expansão capitalista. Outro desafio que ele enfrenta é o da definição do significado do termo "classe média”. Em sociedades com estratificação tão complexa como as latino-americanas, seria 114 impossível reunir, num mesmo grupo, trabalhadores com posturas políticas e ideológicas diversas. Essa desigualdade, que remeteria ao período da escravidão, ${ }^{15}$ contribui tanto para a dominação social quanto para a desorganização do movimento operário: trabalhadores não-manuais de camadas mais elevadas tenderiam a se afastar de outros estratos inferiores, com medo da ameaça de proletarização e, assim, adotariam posições mais conservadoras. Para Saes, enfim, não é suficiente recuperar a noção de classe média em seu sentido clássico, europeu. Apesar dessa reflexão concentrada sobre os setores médios, Saes permanece alinhado à concepção marxista do conflito de classes entre dois polos antagônicos, a burguesia e o proletariado. Essa convicção o leva a afirmar que a classe média não possui uma ideologia própria, mas tende a se alinhar às posições das classes

\footnotetext{
15 Décio Saes cita a pesquisa clássica de Florestan Fernandes sobre a integração do negro na sociedade de classes e a persistência de uma hierarquização que tende a desvalorizar o trabalho manual.
} 
fundamentais de acordo com a conjuntura: "a posição política dos grupos médios depende da conjuntura, do modo como se articulam e se opõem a prática política burguesa e a prática política operária, de seus problemas e tensões" (1974, pp. 38).

A tese de Christine Apesteguy - L'intervention fédérale en Amazonie. Élements pour une définition de l'État Militaire au Brésil, concluída em 1976 - foi concebida em diálogo com o projeto “Amazonie 2000", liderado por Pierre Monbeig no CNRS. Geógrafo francês, Monbeig fora professor da USP entre 1935 e 1946 e já se dedicava ao estudo da Amazônia numa abordagem multidisciplinar, concentrada na análise das forças que pautavam projetos de integração nacional. Sua contribuição foi importante para pesquisadores que pensavam a intervenção do Estado militar, pois ele desconstruía a hipótese de que a história do "pioneirismo" no Norte do país começara a partir do golpe de 1964. O que teria mudado, segundo ele, era sua justificação ideológica. Apesteguy compartilha essa visão em sua pesquisa, que se concentra justamente sobre as estratégias de integração praticadas pelos militares. A nova ideologia que justifica a integração era concebida pelo Estado, mas na condição de instrumento da classe dominante, pois alçava ao status de "interesse nacional" e questão de segurança uma política que servia à expansão capitalista. A autora destaca ainda outras duas funções estatais importantes que aparecem coladas à ideológica: a econômica, de incentivo à acumulação através da criação de estruturas e isenções fiscais; e a policial, coercitiva, que resulta na repressão aos movimentos populares de resistência. Apesar de não ter como objeto um ator social específico, a tese de Apesteguy se assemelha às demais dirigidas por Touraine ao se preocupar com a História - que aparece na primeira parte ao lado da descrição do espaço amazônico - e com as estruturas da dependência, que exercem enorme peso sobre a forma de expansão capitalista na 
região. A autora destaca alguns momentos dessa estratégia, como a criação da Superintendência para o Desenvolvimento da Amazônia (Sudam), em 1966, e o lançamento de dois grandes projetos: o Plano de Integração Nacional, em 1970, e o Segundo Plano Amazonense, de 1974.

Bourgeoisie industrielle et capital étranger au Brésil, tese defendida por Lígia Maria Pereira em 1978, é dedicada à análise do papel da burguesia paulista na implantação e manutenção do "modelo de desenvolvimento capitalista dependente", sobretudo a partir de 1956. Ela dialoga com muitos trabalhos que, após o fracasso do projeto nacional-desenvolvimentista, criticaram setores da classe dominante por seu caráter antinacional, subordinado a interesses estrangeiros. Pereira toma Florestan Fernandes como uma referência importante neste debate. Ela sublinha a centralidade de sua hipótese da dupla determinação, interna e externa, à qual estaria submetida a expansão capitalista 116 em sociedades dependentes, bem como a incapacidade da burguesia nacional de executar um programa de modernização. Carente de hegemonia, esta classe apresentaria uma feição autoritária, sobretudo diante do temor de uma revolução social que saísse de seu controle. Daí seu caráter antinacional. Para Pereira, essa visão é semelhante àquela que Touraine apresenta no livro Les sociétés dépendantes, de 1976: os países periféricos contam com burguesias frágeis, incapazes de liderar projetos nacionais. Elas acabam substituídas pelo Estado que, por sua vez, alia-se ao capital estrangeiro para realizar grandes transformações estruturais. Pereira também se ampara em Crítica à razão dualista, de Francisco de Oliveira que, mesmo fiel ao binômio "capitalismo dependente", teria enfatizado em seu ensaio o caráter capitalista em detrimento da noção de dependência. Essa perspectiva, que Pereira considera a mais adequada, permitiria dar maior destaque aos conflitos internos e ao papel decisivo da burguesia nacional durante o processo de expansão do 
capitalismo dependente, ao lado do Estado e do capital estrangeiro. Daí deriva a hipótese que guia sua pesquisa, emprestada de Francisco de Oliveira: a situação econômica é fundamental para a definição da política econômica, mas esta é acima de tudo política, ou seja, corresponde ao estado da luta de classes no país.

Maria das Graças Grossi também estudou a burguesia em seu doutorado, defendido em 1979. Em Système politique et développement économique: le cas de Minas Gerais (Brésil), a autora recupera o debate sobre o tema, assim como fizera Pereira, mas prefere se concentrar sobre a trajetória da burguesia de Minas Gerais, seu estado de origem. Além do interesse pessoal, a pesquisadora justifica o recorte pela oportunidade de estudar uma região com características particulares no interior da heterogênea estrutura de produção nacional. Grossi propunha um olhar sobre a questão regional e um debate sobre o peso que o regionalismo político exerce sobre o conjunto do país. Essa dupla perspectiva lhe permitiu apresentar a hipótese de que o declínio econômico da burguesia de Minas Gerais não resultou numa perda equivalente de poder político nem de força social, sobretudo em âmbito local. Fenômeno que abriria a possibilidade para se pensar a partir de um "modelo mineiro de desenvolvimento", que não seria idêntico ao nacional.

Ao tratar do sistema político dependente de seu estado, a autora toma como referência a teoria de Touraine, cuja análise não se dá em termos de dominação, mas de influência, pressão e reivindicação. Isso, segundo Grossi, evita o erro comum de tomar as classes sociais como atores diretos no interior do sistema político. Haveria sempre uma mediação entre atores e representação. Nas sociedades dependentes - e Minas Gerais representaria uma dependência dentro da dependência - essa mediação seria ainda mais acentuada. Daí a grande autonomia do sistema político, a ponto de ser possível identificar, em sociedades de enclave, uma "classe 
política" interna sem ligação com a produção local, mas colada a interesses de grupos econômicos estrangeiros. Este seria o caso do sistema político mineiro, um Estado carente de setor produtivo de ponta e dominado por uma burguesia dependente em relação a outras regiões do país.

Em L'union fait la faiblesse. Le commandement général des travailleurs et la politique brésilienne: 1962-1964, tese defendida em 1979, Júlio César Grieco também se concentra na análise de atores sociais em sociedades dependentes. Logo na introdução, ele retoma a trajetória do debate sobre desenvolvimento na América Latina e a ruptura com as teses clássicas que afirmavam sua inevitabilidade, num sentido evolucionista. Neste percurso, as apostas otimistas no caráter progressista da burguesia também ruíram, o que inspirou grandes discussões sobre a conduta dos setores sociais dominantes. $\mathrm{O}$ mesmo não teria ocorrido em relação às classes dominadas, que são objeto da pesquisa de Grieco. Seu foco é sobre 118 o movimento de trabalhadores, com destaque para a forma assumida pelo sindicalismo em países de capitalismo tardio e suas diferenças em relação ao modelo europeu. Uma de suas características peculiares, realçada pelo autor, é a dependência do movimento sindical em relação ao Estado. Essa percepção serve de ponto de partida para Grieco questionar a ideia de que as classes populares brasileiras haviam alcançado um grau elevado de radicalização nos anos anteriores ao golpe de 1964, ao ponto de ameaçarem a ordem social vigente. Essa hipótese, que era sustentada tanto por setores da esquerda quanto da direita, apontava para um incremento de formas de organização autônoma dos trabalhadores e se tornou um parâmetro para vários estudos sobre a crise do populismo durante os anos 1960. Grieco propõe uma leitura oposta que sublinha - como sugere o título de sua tese - a fraqueza da classe trabalhadora, organizada por sindicatos cujas direções eram bastante dependentes do sistema político. 
Ghislaine Duque estuda o movimento camponês em Casa Nova: interventions du pouvoir et stratégies paysannes. Un «municipe»du «sertão bahiano» à l'heure de la modernisation, tese defendida em 1980. A partir do contato com a população afetada pela construção da barragem de Sobradinho, na fronteira dos estados da Bahia, Pernambuco e Piauí, Duque tenta responder a algumas questões: em quais condições aqueles camponeses, "clientes" de programas de assistência social, poderiam se converter em atores? Como e quando eles passariam à ação? De que forma poderiam superar o limite de demandas econômicas, imediatas, e assumirem uma conduta mais ampla e autônoma? Essas perguntas aproximaram a autora das discussões que Touraine fazia sobre os novos movimentos sociais, mas ela não se restringiu a este marco teórico. Ainda no Brasil, decidiu cursar disciplinas na PUC do Rio de Janeiro, onde teve contato com Ivandro da Costa Sales, e no Museu Nacional, onde um grupo ligado a Moacir Palmeira realizava pesquisas sobre o movimento camponês no Nordeste. Esses contatos lhe permitiram conhecer a obra de outros autores brasileiros que aparecem em sua bibliografia, como Florestan Fernandes, Fernando Henrique Cardoso, Costa Pinto, Juarez Brandão Lopez ou Francisco de Oliveira.

Ao analisar as referências bibliográficas das nove teses, agora tomadas em conjunto, é possível identificar alguns textos e autores recorrentes. Fernando Henrique Cardoso está entre os mais citados, com várias obras, entre as quais se destacam Notas sobre Estado e dependência, com quatro aparições, Empresário industrial e desenvolvimento econômico, cinco vezes, e Dependência e desenvolvimento na América Latina, elaborado com Enzo Faletto, lembrado em seis trabalhos. Crítica à razão dualista, de Francisco de Oliveira, também é citado em seis teses. Octavio Ianni é outra presença constante: Industrialização e desenvolvimento social no Brasil e $O$ colapso do populismo no Brasil são mencionadas quatro vezes 
cada. O livro A industrialização de São Paulo, do historiador Warren Dean, aparece como referência para cinco pesquisas. Há ainda um autor unânime: Celso Furtado é lembrado em todas as nove teses, por diversas obras. E pertence a ele a mais citada, oito vezes: Formação econômica do Brasil.

A lista de autores e obras também nos permite identificar alguns centros de maior influência. O primeiro, sem dúvida, é a sociologia paulista, representada por Cardoso e Ianni, mas também por autores pioneiros em estudos sobre o meio operário, como Juarez Brandão Lopes e Azis Simão. Já Florestan Fernandes, mestre dessa geração, só aparece com maior frequência nas bibliografias de teses defendidas a partir da segunda metade dos anos 1970, quando já estavam publicadas duas de suas obras mais citadas: Capitalismo dependente e classes sociais na América Latina, de 1973, e A revolução burguesa no Brasil, de 1975. Em contrapartida, são raras as referências a seus trabalhos anteriores à década de 1970, 120 em que pesavam questões de método e teoria das ciências sociais. Outros nomes que aparecem, porém com menor intensidade do que os "paulistas", são os de autores ligados aos debates sobre a dependência num viés marxista, como Ruy Mauro Marini.

As referências também variam de acordo com o tema da pesquisa, o que fica muito claro quando separamos trabalhos que se concentram sobre o espaço urbano - sindicatos, organizações patronais, aspectos da industrialização daqueles voltados ao meio rural. Enquanto, nos primeiros, são mais numerosas as citações de autores vinculados à cadeira I de sociologia da USP ou à teoria da dependência, em suas variadas feições, nos últimos aparecem referências específicas que remetem a outras escolas ou tradições. São os casos, especialmente, das teses de Aspásia Camargo e Ghislaine Duque, ambas dedicadas ao movimento camponês no Nordeste brasileiro. Sem ignorarem a questão mais ampla das sociedades dependentes e de seus atores sociais, 
presente em todas as teses, elas se aproximam de autores e textos que dão maior atenção à questão regional em seus trabalhos. É o caso de nomes vinculados ao Museu Nacional, como Moacir Palmeira, lembrado por sua tese em francês, Latifundium et capitalisme au Brésil: lecture critique d'un débat, ou Afrânio Garcia Jr., com sua dissertação Terra de trabalho. As teses de Camargo e de Duque também compartilham outras obras de referência, como A terra e o homem do nordeste, de Manuel Correia de Andrade, Os sertões, de Euclides da Cunha, e Cangaceiros e fanáticos, de Rui Facó. Ambas também citam textos de Caio Prado Jr. sobre a questão agrária no Brasil. Mas há diferenças: Aspásia Camargo lembra diversas obras de Gilberto Freyre, autor ausente na bibliografia de Ghislaine Duque. Nesta, a autora mais citada é Maria Isaura Pereira de Queiroz: são sete trabalhos sobre messianismo e tradição no meio rural brasileiro.

Essa presença marcante de Queiroz na bibliografia de uma das teses abre novos caminhos para nossa reflexão. Vinculada à tradição da cadeira II de sociologia da USP, ela não teria camuflado seu mal-estar diante da predileção de Touraine pelos membros da cadeira I, durante sua estadia em São Paulo. ${ }^{16}$ Isso não foi obstáculo, no entanto, para que ela se tornasse a maior referência da pesquisa de Duque, orientanda que talvez seja a mais distante da abordagem privilegiada por seu orientador não só pela escolha de seu objeto - os camponeses do Nordeste, também estudados por Aspásia Camargo - mas, sobretudo, por ter sublinhado em sua tese o peso de aspectos culturais que seriam próprios desse ator, como o messianismo, tema em que Queiroz era e ainda é uma referência incontornável. Essa liberdade

\footnotetext{
${ }^{16}$ Segundo Touraine, quando ele manifestou sua simpatia por Fernando Henrique Cardoso e outros pesquisadores da cadeira I "foi um drama. Porque o pessoal da minha cadeira, em especial Maria Isaura [Pereira de Queiroz], ficou furioso. Maria Isaura não falou mais comigo pelo resto da sua vida. O que era uma bobagem, porque tanto faz a cadeira I ou a cadeira II." (informação verbal, entrevista cedida em fevereiro de 2018).
} 
da qual Duque desfrutou para escolher os rumos de seu trabalho foi compartilhada pelos outros doutorandos de Touraine, segundo apurei em entrevistas: o sociólogo francês não impunha sua perspectiva ou sua agenda de pesquisas aos orientandos que se dedicavam ao Brasil. Neste sentido, as referências constantes a autores vinculados direta ou indiretamente à cadeira I de sociologia da USP não seria fruto da orientação de Touraine, mas da escolha dos próprios pesquisadores que, mesmo distantes, compartilhavam muitas das questões que animavam as ciências sociais brasileiras. Sobretudo aquelas vinculadas à longa tradição de estudos - que remetia à CEPAL e a Celso Furtado, presente em todas as teses - dedicada a identificar os obstáculos ao desenvolvimento nos países periféricos. Preocupação que, a partir de 1964, se converteu num esforço de interpretação sobre as causas do colapso do populismo e do nacional-desenvolvimentismo, colado à reavaliação da conduta dos 122 atores sociais. Temas difundidos em que a presença de expoentes da escola paulista era marcante.

Mas até que ponto essa visão sobre atores sociais e dependência no Brasil pode ser estendida para outros países latino-americanos? Para responder a essa questão, analisei o conteúdo de três teses sobre o Chile orientadas por Touraine no mesmo período: La stabilité politique du Chili: quelques hypothèses sur le rôle du mouvement ouvrier, de Francisco Zapata Schaffeld, defendida em 1970; Le comportement ouvrier au Chili, de Roberto Décio de las Casas, de 1975; e Voie légale vers le socialisme? La tactique de l'Unité Populaire et les institutions politiques chiliennes, elaborada por Susana Bruna del Campo e concluída em 1975. É possível notar já pelos títulos dessas pesquisas que elas compartilham com os trabalhos dedicados ao Brasil o interesse pelos atores sociais e sobre suas formas de expressão política. As duas primeiras tratam do movimento operário, enquanto a terceira analisa a tática da Unidade Popular, aliança que deu expressão às demandas 
das classes dominadas chilenas. Outro dado interessante é que a tese de Zapata Schaffeld foi elaborada num período de ascensão do movimento operário no país, enquanto as de Décio de las Casas e Bruna del Campo se encerraram após o golpe militar de 1973, que derrubou Salvador Allende. Veremos que essa mudança radical de conjuntura teve peso sobre seus trabalhos.

Zapata Schaffeld iniciou sua pesquisa em Santiago, em 1967, junto ao Instituto Latinoamericano de Planificación Económica y Social (ILPES), que era dirigido por José Medina Echavarría e Fernando Henrique Cardoso. Este aparece em sua bibliografia ao lado de outros brasileiros, como Juarez Brandão Lopez, Celso Furtado, Leôncio Martins Rodrigues, Azis Simão e Francisco Weffort. Cardoso e Furtado são lembrados na tese de Décio de las Casas, que dialoga com nomes vinculados a outra vertente da teoria da dependência, como Theotônio dos Santos e André Gunder Frank - algo que também faz Bruna del Campo ao citar Ruy Mauro Marini.

Na tese de Zapata Schaffeld, um dos pontos de partida é a ideia de que o sistema político chileno se consolidou mais cedo do que em outros países da América Latina, antes que a pressão das massas populares se fizesse sentir. Quando estas apareceram, logo foram absorvidas pelo regime e passaram a expressar suas demandas através de um sindicalismo organizado e autônomo, o que contribuía para legitimar as instituições políticas. A autonomia dos sindicatos chilenos contrastava com a situação do movimento operário de outros países. No Brasil, por exemplo, encontraríamos um sindicalismo controlado pelo Estado, cuja descrição o autor retira de textos de Azis Simão e Leôncio Martins Rodrigues. Para Zapata Schaffeld, em suma, os atores sociais estariam mais consolidados no Chile do que em outros países latino-americanos. O movimento operário, em especial, teria se integrado ao sistema político 
e passado a influenciá-lo, o que o aproximava mais de um modelo de experiência europeu do que latino-americano. Há uma visão otimista do autor a respeito da estabilidade e abrangência das instituições políticas e da força dos atores sociais e chilenos. Uma leitura compreensível naquela conjuntura em que o país abrigava uma democracia supostamente aberta à participação popular. Talvez essa impressão explique o fato de Zapata Schaffeld não colocar a teoria da dependência como base de suas reflexões: ela é lembrada, mas ele não considera a falta de controle dos atores sociais nacionais sobre o sistema econômico como um fator condicionante da sociedade chilena.

Nas outras duas teses, defendidas após o golpe militar, a postura é outra. Tanto para Décio de las Casas quanto para Bruna del Campo, a dependência econômica é um dos motivos fundamentais para o fracasso da democracia popular chilena. Ela ajuda a moldar, para o primeiro, o comporta124 mento dos atores sociais internos. Inclusive do movimento operário, que foi o objeto de sua pesquisa. Bruna del Campo também parte da teoria de dependência para discutir a estrutura social chilena e retoma Ruy Mauro Marini, por exemplo, para discutir a existência de uma classe trabalhadora superexplorada e excluída do sistema político, o que vai em sentido contrário à tese central de Zapata Schaffeld. O golpe contra a Unidade Popular inspirou uma leitura mais pessimista expressa nas duas últimas teses, mas os três trabalhos perseguem objetivos idênticos: compreender as especificidades do desenvolvimento capitalista na periferia e a conduta dos atores sociais neste processo. A mudança na conjuntura só teve reflexo, portanto, nas hipóteses e conclusões das teses: se o Chile democrático permitia interpretar sua história a partir de uma aproximação maior à experiência europeia, a ditadura de Pinochet exigia uma abordagem mais colada à ideia de um modelo de desenvolvimento dependente. 


\section{Conclusão}

Em seus textos dedicados à América Latina, Touraine levantava questões semelhantes, o que o aproximava dessa perspectiva então dominante na sociologia brasileira. Mas sua abordagem não era idêntica. Ao definir um rígido "modelo dependente de desenvolvimento", que apresentei anteriormente, e ao enfatizar em suas análises os desvios deste em relação ao caminho clássico da modernização trilhado por países europeus, o sociólogo francês se afastou de alguns pressupostos fundamentais do pensamento social da Escola Paulista. Uma forma de interpretarmos essa ruptura é através da comparação entre o lugar da periferia e de seu alcance heurístico nas perspectivas de Touraine e de alguns expoentes da sociologia da USP.

Ao discutir o pensamento social dessa Escola a partir de um trecho do prefácio de Florestan Fernandes à primeira edição de A sociologia numa era de revolução social, de 1962, Elide Rugai Bastos acredita:

ser possível apontar para uma afirmação implícita na análise, que parece ancorar a definição do objeto de investigação: a partir da periferia percebe-se melhor o movimento da sociedade, possibilitando a verificação dos princípios que a estruturam. Aqui está a gênese do método. Florestan explicita essas intenções levantando as possibilidades de reflexão sociológica desenvolvida por seu grupo inscrever-se no debate internacional. (2002, p. 189, grifo original)

Ao desviar-se da norma, a modernização dos países periféricos exige retificações de abordagens clássicas da sociologia e a construção de novos modelos. Mas estes não se encerram em si: para Florestan Fernandes, eles devem contribuir para o debate sociológico como um todo, além das fronteiras nacionais. Daí a posição "quase privilegiada" que ele atribui aos sociólogos brasileiros. A periferia sobre a qual e de onde eles falam não é 
apenas um objeto de estudo. Ela é "o objetivo, unidade de pesquisa, o desafio à compreensão, a busca de um suporte teórico e o método de investigação" (Bastos, 2002, pp. 186).

A sociologia do desenvolvimento proposta por Touraine não tem a mesma dimensão. Embora dialogue com a perspectiva que sublinha aspectos originais da História e da realidade latino-americana e valorize as contribuições do pensamento social da região - da teoria da dependência, em particular - à sociologia em geral, o sociólogo francês não rompe completamente com um lugar de fala que toma a experiência europeia como parâmetro definitivo de análise. Este ponto de vista - do qual muito dificilmente ele poderia se afastar - é o da modernidade europeia, sobretudo francesa. É a essa realidade que sempre remete seu pensamento, mesmo quando ele olha para outras sociedades. É dela também que ele retira seus objetivos de pesquisa, os desafios à compreensão e as bases teóricas e metodológicas da inves126 tigação, mesmo quando afirma a incompatibilidade entre um modelo de análise europeu e a realidade das sociedades dependentes. É neste ponto, aliás, que surge uma tensão crucial, não resolvida: diante da impossibilidade de compreender os atores e a ação social nessas sociedades a partir de uma abordagem clássica, Touraine sublinha a fraqueza, a imperfeição ou o desvio à norma. A inadequação entre a realidade latino-americana e a teoria social gera um impasse que pesa sobre a primeira: nosso problema é que não somos plenamente modernos.

Conhecer sua posição também nos ajuda a entender a predileção pelos estudos sobre a industrialização e os conflitos urbanos no Brasil que ele revelou durante sua passagem pela USP, no início dos anos 1960: esses temas permitiam um vínculo mais imediato com o debate sobre modernidade e modernização que sempre o preocupou. Algo que ele me revelou em entrevista recente, quando o questionei sobre o que o levou a se aproximar da Cadeira I de Sociologia: 
A única coisa que posso dizer é que tinha essa gente da sociologia do trabalho e gente que eu me sentia menos próximo como Maria Isaura [Pereira de Queiroz], que era realmente a ideia do Brasil rural, da tradição. Coisas de boa qualidade, porém mais distantes do que eu me ocupava, da modernização, da industrialização. (informação verbal) ${ }^{17}$

Ou seja: as pesquisas voltadas exclusivamente ao meio rural ou a atores considerados tradicionais que não se propusessem a pensá-los em relação com o urbano lhe pareciam alheios ao debate sobre a modernização. Uma separação rígida entre dois mundos - o arcaico e o moderno - que corre o risco de recair numa visão dualista das sociedades dependentes. A periferia não atinge em seu pensamento o status de método que conquistou entre alguns expoentes da sociologia paulista: os percalços da modernização latino-americana não lhe parecem elementos constitutivos da modernidade em si e não podem, portanto, dar grandes contribuições à compreensão do todo. Não revelam, para Touraine, caminhos específicos no interior da experiência moderna, mas marginais em relação a ela, exóticos, dotados de um caráter heurístico que se limitaria às suas próprias fronteiras periféricas. Em suma: a marginalidade se sobrepõe à especificidade.

Mas essas características não apagam a importância de seu intercâmbio com a sociologia brasileira. Touraine teve uma sensibilidade rara entre intelectuais estrangeiros diante da realidade da América Latina e contribuiu para a construção de uma sociologia crítica de seu processo de modernização. Conhecer os termos desses debates e os contextos nos quais eles se inseriram nos permite identificar melhor aspectos da História do pensamento social brasileiro e latino-americano. Afinal, o olhar do estrangeiro talvez ajude a revelar alguns aspectos que nós, imersos em nossos conflitos, temos dificuldades para enxergar.

17 Entrevista cedida em fevereiro de 2018. 


\section{Flávio da Silva Mendes}

é doutor em Sociologia pela Universidade Estadual de Campinas (Unicamp) e atualmente conclui o pós-doutorado pelo departamento da área na mesma universidade.

\section{Bibliografia}

BASTOS, Elide R. 2002. Pensamento social da escola sociológica paulista. In: MICELI, Sérgio. O que ler na ciência social brasileira: 1970-2002. São Paulo: Anpocs.

CHAPOULIE, Jean-Michel. 1991. La seconde fondation de la sociologie française, les États-Unis et la classe ouvrière. Revue Française de Sociologie, v. 32, n. 3, pp. 321-364.

CROZIER, Michel. 1996. Alain Touraine: a pioneer in the new french sociology. In: CLARK, Jon; DIANI, Marco. Alain Touraine. Londres: Falmer Press.

GADEA, Carlos A.; SCHERER-WARREN, Ilse. 2005. A contribuição de Alain Touraine para o debate sobre sujeito e democracia latinoamericanos. Revista de Sociologia e Política, n. 25, nov. 2005.

LOPES, José Sérgio L. 2013. Touraine e Bourdieu nas ciências sociais brasileiras: duas recepções diferenciadas. Sociologia $\mathcal{E}{ }^{2}$ Antropologia, v. 3, n. 5, pp. 43-79, jun. 2013.

LOPES, José Sergio L.; PESSANHA, Elina; RAMALHO, José Ricardo. 2012. Esboço de uma história social da primeira geração de sociólogos do trabalho e dos trabalhadores no Brasil. Educação E Sociedade, v. 33, n. 118, pp.115-129.

OOMMEN, Tharailath K. 1996. Social movements in a comparative perspective: situating Alain Touraine. In: CLARK, Jon; DIANI, Marco. Alain Touraine. Londres: Falmer Press.

PIRES-SABÓIA, Anita (org.). 2000. Catalogue général de thèses soutenues en France sur le Brésil: 1823-1999. Cahiers sur le Brésil Contemporain, Paris. Hors série.

PULICI, Carolina. 2007. De como o sociólogo brasileiro deve praticar seu ofício: as cátedras de sociologia da USP entre 1954 e 1969. Perspectivas, v. 31, pp. 97-120.

ROMÃO, Wagner M. 2006. Sociologia e política acadêmica nos anos 1960: a experiência do Cesit. São Paulo: Humanitas.

SCOTT, Alan. 1996. Movements of modernity: some questions of theory, method and interpretation. In: CLARK, Jon; DIANI, Marco. Alain Touraine. Londres: Falmer Press. 
TANGUY, Lucie. 2008. Retour sur l'histoire de la sociologie du travail en France: place et rôle de l'Institut des sciences sociales du travail. Revue Française de Sociologie, v. 49, n. 4, pp. 723-761.

TOURAINE, Alain. 1961. Industrialisation et conscience ouvrière à São Paulo. Sociologie du Travail, v. 3, n. 4, pp. 77-95.

TOURAINE, Alain. 1973. Production de la société. Paris: Editions du Seuil.

TOURAINE, Alain. 1976. Les sociétés dépendantes: essais sur l'Amérique Latine. Paris: Editions Duculot.

TOURAINE, Alain. 1977. Un désir d'histoire. Paris: Stock.

TOURAINE, Alain. 1988. La parole et le sang: politique et societé en Amérique Latine. Paris: Odile Jacob. 


\section{ALAIN TOURAINE E 0 BRASIL: ATORES SOCIAIS E DEPENDÊNCIA EM DIÁLOGOS DOS ANOS 1970}

\section{FLÁVIO DA SILVA MENDES}

Resumo: Este artigo apresenta uma parte dos diálogos de Alain Touraine com autores brasileiros. Concentro-me sobre a década de 1970, período em que o sociólogo francês orientou nove teses sobre o Brasil em universidades da região parisiense, todas dedicadas ao estudo de atores sociais no contexto de sociedades dependentes. Antes de analisar o conteúdo dessas pesquisas, apresento de forma breve alguns fundamentos da teoria social tourainiana, o contexto de seus primeiros contatos com a sociologia brasileira e os elementos que compõem o "modelo de desenvolvimento dependente", que Touraine elaborou para pensar a América Latina. A seguir, discuto a presença deste modelo nas teses de seus orientandos e alguns limites dessa abordagem.

Palavras-chave: Alain Touraine; Atores Sociais; Dependência; Sociologia Brasileira.

\section{ALAIN TOURAINE AND BRAZIL: SOCIAL ACTORS AND DEPENDENCY IN DIALOGUES OF THE 1970 S}

Abstract: This article shows part of the dialogues of Alain Touraine with Brazilian authors. I focus on the 1970s, when the French sociologist supervised nine theses on Brazil in universities in the Paris region, all dedicated to the study of social actors in the context of dependent societies. Before analyzing the content of these researches, I briefly present some fundaments of Touraine's social theory, the context of his early contacts with Brazilian sociology, and the elements that compose the "model of dependent development" that he elaborated to think of Latin America. Next, 
Resumos $\mid$ Abstracts

I discuss the presence of this model in the theses of its students and some limits of this approach.

Keywords: Alain Touraine; Social Actors; Dependency, Brazilian Sociology.

Recebido: 06/04/2018 Aprovado: 25/02/2019 